\title{
Corrigendum: Double Reversing Z Plasty for Tracheastomal Stenosis After Total Laryngectomy
}

(1) Burak Karabulut, ' (1) Hakan Avcl, ${ }^{1}$ (1) Sedat Aydın²

'Department of Otolaryngology,
Kartal Dr. Lütfi Kırdar Training and
Research Hospital, İstanbul, Turkey
2Department of Oral and
Maxillofacial Surgery, Istanbul
University Faculty of Medicine,
Istanbul, Turkey

\section{Corrigendum}

South. Clin. Ist. Euras. 2020;3I(3):26I-264

DOI: $10.14744 /$ scie.2020.61224

The list of authors was incomplete in the original publication.

The correct list is:

Burak Karabulut, Hakan Avcı, Sedat Aydın 